\title{
Las floraciones de cianobacterias tóxicas comprometen el uso del agua del Río Negro, Uruguay
}

\author{
Toxic cyanobacterial blooms compromise the use of the Río Negro \\ water, Uruguay
}
Blooms de cianobactérias tóxicas comprometem o uso da água do Rio Negro, Uruguai

Sylvia Bonilla ${ }^{1,2 *}$ https://orcid.org/0000-0002-1772-9899

Luis Aubriot ${ }^{1,2}$ https://orcid.org/0000-0001-9673-6853

Signe Haakonsson ${ }^{1,2}$ https://orcid.org/0000-0001-8205-3672

Mariana Illarze ${ }^{2}$ https://orcid.org/0000-0001-9286-9384

Ismael Díaz ${ }^{4}$ https://orcid.org/0000-0003-3176-1753

Beatriz Brena ${ }^{1,3}$ https://orcid.org/0000-0002-8056-7167

*Autor de contacto: sbon@fcien.edu.uy

${ }^{1}$ Grupo de Ecología y Fisiología de Fitoplancton.

${ }^{2}$ Sección Limnología, IECA, Facultad de Ciencias, Universidad de la República. Montevideo, Uruguay.

3Área Bioquímica, Facultad de Química, Universidad de la República. Montevideo, Uruguay.

${ }^{4}$ Laboratorio de Desarrollo Sustentable y Gestión Ambiental del Territorio, IECA, Universidad de la República. Montevideo, Uruguay.

Recepción: 6 Abril 2021 Aprobación: 12 Octubre 2021

Esta obra está bajo una Licencia Creative Commons Atribución NoComercial 4.0 Internacional. 
Resumen: Las floraciones de cianobacterias tóxicas generan impactos negativos a nivel ambiental, económico, y en la salud humana y animal. Se realizó un análisis de datos históricos (1989-2020, $n=423$ ) y un experimento de enriquecimiento de nutrientes para estudiar las cianobacterias del Río Negro, principal río interno del país. En base a indicadores cuantitativos (biovolumen, abundancia de células de cianobacterias y observación visual), se definieron cuatro niveles de peligrosidad de exposición a cianobacterias tóxicas. Las cianobacterias más frecuentes (Microcystis sp. y Dolichospermum sp.) son productoras potenciales de diversas toxinas, incluyendo algunas que no han sido analizadas aún en Uruguay. Se advierte un deterioro ambiental creciente desde el año 2000, pautado por el aumento de la biomasa de cianobacterias y las concentraciones de toxinas (microcistinas). Los nutrientes en el agua indican eutrofización avanzada, asociada al incremento del área agrícola de la cuenca. Los resultados experimentales demostraron el papel clave de los nutrientes y el tiempo de residencia en el favorecimiento de estos organismos. Las floraciones tóxicas de cianobacterias amenazan seriamente los múltiples servicios ecosistémicos que brinda el río, siendo indispensable la instrumentación de planes de monitoreo de cianobacterias y medidas de manejo para controlar la eutrofización a largo plazo.

Palabras clave: calidad de agua, eutrofización, embalses, nutrientes, fitoplancton.

Abstract: Toxic cyanobacterial blooms generate negative environmental, economic, and health impacts. We carried out an analysis of historical limnological data (1989-2020, n = 423) and we performed a nutrient enrichment experiment to study the cyanobacteria of Río Negro, the largest internal river of Uruguay. We defined four hazard levels of exposure to toxic cyanobacteria based on quantitative indicators (biovolume and abundance of cyanobacterial cells and visual observation). The most common cyanobacteria (Microcystis sp. and Dolichospermum sp.) are potential producers of various toxins, including some that have not yet been analyzed in Uruguay. Accelerating environmental deterioration since 2000 has been shown by an increase of cyanobacteria biomass and concentrations of toxins (microcystins). Nutrient concentrations indicated advanced eutrophication, associated with the increase in the area devoted to agriculture of the watershed. Experimental results demonstrated the key role of nutrients and residence time in favoring these organisms. Toxic cyanobacterial blooms seriously threaten the multiple ecosystem services provided by the river, making it essential to implement cyanobacteria monitoring, and management plans to control eutrophication in the long term.

Keywords: water quality, eutrophication, reservoirs, nutrients, phytoplankton.

Resumo: Blooms de cianobactérias tóxicas geram impactos ambientais e econômicos negativos, alem de danos à saúde humana e animal. Análise de dados históricos (19892020, $n=423$ ) e um experimento de enriquecimento de nutrientes foram realizados para estudar as cianobactérias do Río Negro, o principal rio interno do Uruguai. Com base em indicadores quantitativos (biovolume e abundância de células cianobacterianas e observação visual) foram definidas quatro categorias de perigosidade de exposição a 
toxinas. As cianobactérias mais comuns (Microcystis sp. e Dolichospermum sp.) são produtoras potenciais de várias toxinas, algumas das quais nunca foram analisadas en Uruguai. Elevadas biomassas de cianobactérias e concentrações das toxinas (microcistinas) foram encontradas desde 2000 com tendência a aumentar casos em categorias de alta perigosidade e alertando para a deterioração ambiental, a última década. Concentrações altas de nutrientes na água indicam eutrofização avançada associado com o aumento da área da bacia dedicada à agricultura. Os resultados experimentais demonstraram o papel fundamental dos nutrientes e do tempo de residencia no favorecimento de cianobactérias. A proliferação de cianobactérias tóxicas ameaçam seriamente os múltiplos serviços ecossistêmicos fornecidos pelo rio, tornando essencial a implementação de monitoramento de cianobactérias, planos de manejo e monitoreamento para controlar a eutrofização em longo prazo.

Palavras-chave: qualidade da água, eutrofização, reservatórios, nutrientes, fitoplâncton.

\section{INTRODUCCIÓN}

A nivel global, la agricultura es el principal factor asociado a la eutrofización de los ecosistemas acuáticos continentales, debido al aporte de nutrientes al agua derivados de la fertilización (Moss, 2008; Ramankutty, et al., 2018). Una de las principales consecuencias de la eutrofización es la aparición de altas acumulaciones de biomasa de cianobacterias (floraciones) (Huisman, et al., 2018), que alteran el olor y el sabor del agua, y pueden producir distintos tipos de cianotoxinas peligrosas para la salud humana y animal (van Apeldoorn, et al., 2007). Las floraciones tienen impactos negativos para la sociedad, como aumentos en los costos de potabilización, restricciones para el riego, cierre de zonas recreativas, o incluso el impedimento total del uso del agua (Paerl y Otten, 2013; Chorus y Welker, 2021).

En los ecosistemas lóticos, las actividades antrópicas que afectan el flujo y la circulación natural del agua generan condiciones propicias para las floraciones (Palmer y Ruhi, 2019). Por ejemplo, la construcción de embalses para la generación de energía eléctrica es una práctica muy extendida en América del Sur (Tundisi, et al., 1998; Palmer y Ruhi, 2019). En los embalses, el tiempo de residencia controlado artificialmente cumple un papel importante en la acumulación y el lavado de la biomasa de fitoplancton aguas abajo (Davis y Koop, 2006; Rangel, et al., 2012).

El Río Negro es el principal cuerpo de agua lótico interno de Uruguay, con un caudal promedio de $930 \mathrm{~m}^{3} \mathrm{~s}^{-1}$ (cerca de la desembocadura), y atraviesa el territorio de este a oeste, confluyendo en el río Uruguay (Alonso, et al., 2019) 
(Figura 1). Su cuenca $\left(68.200 \mathrm{~km}^{2}\right)$ ocupa el $39 \%$ del territorio del país y acoge actividades como la ganadería extensiva, la agricultura (secano: trigo, sorgo, soja y maíz; cultivos regados y frutales) y la forestación (FAO y Uruguay. Ministerio de Vivienda Ordenamiento Territorial y Medio Ambiente, 2015; IBGE, 2018). El río se utiliza con múltiples finalidades, entre las que se destacan tres grandes represas construidas sobre el cauce principal: Rincón del Bonete (de ahora en adelante lo llamaremos "Bonete") $\left(1.070 \mathrm{~km}^{2}\right)$, Baygorria $\left(100 \mathrm{~km}^{2}\right)$ y Palmar $\left(320 \mathrm{~km}^{2}\right)$ (Figura 1), que generan el 38\% ( 593 MW) de la energía hidroeléctrica del país (Chalar, et al., 2014; Patrone, 2014). Los tres embalses difieren en su profundidad ( $Z_{\max }$ aproximada: 30, 25 y $30 \mathrm{~m}$, Aubriot com. pers.) y tiempo de residencia (196, 14 y 50 días, promedios 2009-2016, para Bonete, Baygorria y Palmar, respectivamente) (Uruguay. Ministerio de Vivienda Ordenamiento Territorial y Medio Ambiente, DINAMA, 2018). Los caudales varían según la estación, siendo mayores generalmente en otoño e invierno (Chalar, et al., 2014). El régimen de lluvias y el manejo de los embalses condiciona la dinámica del tiempo de residencia, mayor generalmente en Bonete (fuertemente regido por el manejo) y menor en Baygorria, siendo un embalse de paso entre los otros (Uruguay. Ministerio de Vivienda Ordenamiento Territorial y Medio Ambiente, DINAMA, 2018). El agua del río también se utiliza para potabilización, riego, pesca artesanal, cultivo de esturión, recreación y como abrevadero para el ganado (Uruguay. Ministerio de Vivienda Ordenamiento Territorial y Medio Ambiente, DINAMA, 2018). Los valores de nutrientes en el agua (nitrógeno y fósforo) indican un estado hipereutrófico en los embalses (promedios del período 2009-2013: 114 y $725 \mu \mathrm{gL}^{-1}$, para fósforo total y nitrógeno total, respectivamente) (Alonso, et al., 2019; Cunha, et al., 2013), en sintonía con las tendencias generales registradas en las principales cuencas hidrográficas del país (Chalar, 2009; Bonilla, et al., 2015; Aubriot, et al., 2017; Chalar, et al., 2017; Kruk, et al., 2019). Se han registrado floraciones de cianobacterias tóxicas en los embalses antes mencionados y en playas del río (Chalar, et al., 2014; González-Piana, et al., 2017, 2018), muchas veces formando espumas visibles a simple vista o desde imágenes satelitales

(Aubriot, et

al., 2020). 

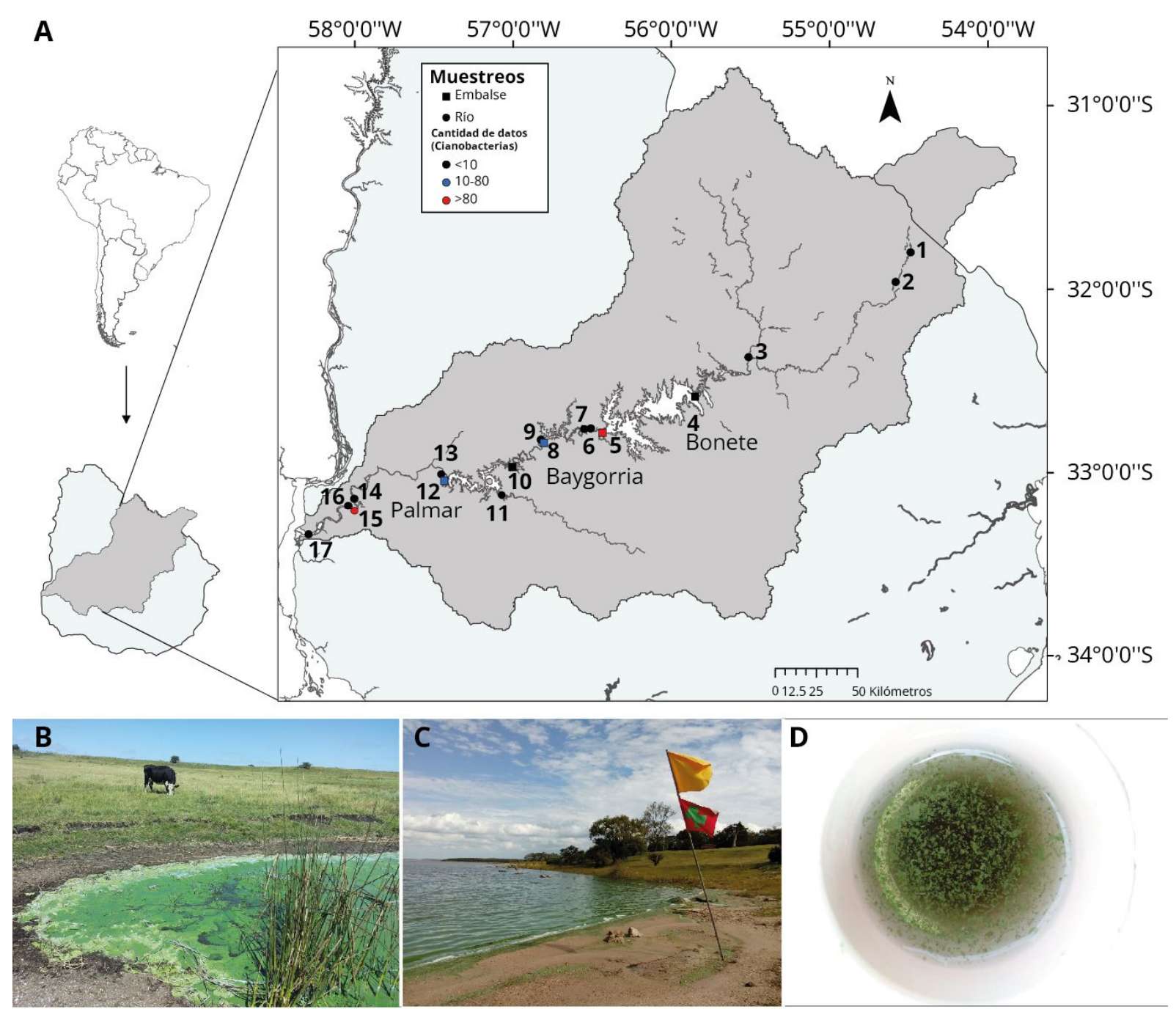

Figura 1. Mapa del Río Negro y su cuenca (área gris), Uruguay, con los sitios de estudio (1 a 17), los colores indican el número de datos disponibles (ver inserto con los códigos) (A). Fotos (B: E. Font, 11/03/2015, y C y D: L. Aubriot, 22/03/2021): espuma de cianobacterias en predio ganadero, Bonete (B), y en playa de Palmar, con bandera sanitaria (C). Cianobacterias en muestra de Palmar (D).

Dadas estas condiciones, la instalación de una planta de celulosa de gran porte aguas abajo del embalse de Bonete implica grandes desafíos ambientales (UPM II, de UPM-Kymmene Corporation, Finlandia; producción estimada $\sim 2$ millones de toneladas secas de pasta por año) (Uruguay. Ministerio de Vivienda Ordenamiento Territorial y Medio Ambiente, DINAMA, 2019a). Por lo tanto, es fundamental poder contar con una evaluación global del ecosistema que permita una gestión adecuada, asegurando el desarrollo sostenible y la coexistencia de diversas actividades antrópicas dependientes del río y su cuenca (Uruguay. Ministerio de Vivienda Ordenamiento Territorial y Medio Ambiente, DINAMA, 2012). Si bien se han generado series temporales de datos limnológicos 
consistentes a partir de 2009 (Uruguay. Ministerio de Medio Ambiente, 2020), no se han analizado en forma integrada a las cianobacterias y las cianotoxinas que aparecen en el río, y la influencia combinada del flujo del agua y los nutrientes como factores que inciden en las floraciones. Este trabajo tuvo dos objetivos, 1) realizar un análisis sinóptico de la información histórica sobre las cianobacterias planctónicas, las cianotoxinas y los principales parámetros ambientales en el Río Negro; y 2) mediante una aproximación experimental, evaluar el papel del tiempo de residencia y los nutrientes en el crecimiento de las poblaciones de cianobacterias y las concentraciones de microcistinas totales.

\section{MATERIALES Y MÉTODOS}

\section{Datos históricos de nutrientes, uso del suelo y cianobacterias}

Los datos de la concentración de nitrógeno total (NT) y de fósforo total (PT) se obtuvieron del portal abierto Observatorio Ambiental de la DINAMA (OAN) (Uruguay. Ministerio de Medio Ambiente, 2020), con información de los embalses (Bonete: BO, Baygorria: BA y Palmar: PA) y tramos lóticos (Figura 1: todos los sitios, excepto el 15), período 2000 a 2019 ( $n=628$ y 616, NT y PT, respectivamente). Se utilizó la base de datos de la Sección Limnología (Bonilla, et al., 2015), incluyendo registros de fitoplancton, biomasa de cianobacterias, concentración de clorofila a $(\mathrm{Clo} a)$, datos de toxinas $(n=169)$ y nutrientes totales. A dicha base de datos se incorporó información proveniente de informes técnicos, artículos referidos a la presencia de cianobacterias (Pérez, et al., 1999; Chalar, et al., 2010; González-Piana, et al., 2017, 2018; Uruguay. Ministerio de Vivienda Ordenamiento Territorial y Medio Ambiente, DINAMA, 2018; Estudio Ingeniería Ambiental, 2019) y datos no publicados de la Sección Limnología (biovolumen de cianobacterias y microcistinas totales y sus variantes), obteniendo una matriz final con 423 registros.

Para visualizar tendencias en la concentración de nutrientes (NT y PT) a lo largo del tiempo, los datos se clasificaron por tipo de ambiente (embalses y tramos lóticos), y se calculó la mediana y los cuantiles extremos $(0,10$ y 0,90) para ventanas temporales entre los años en los que se contaba con información de uso del suelo (ver más abajo).

La información disponible de toxinas se restringe a microcistinas (MC) (en $\mu^{-1} \mathrm{~L}^{-1}$ y por unidad de peso de biomasa cianobacteriana, seco: $\mu g g$ g.s. ${ }^{-1}$ y fresco: $\mu \mathrm{gmm}^{-3}$ ), microcistinas totales (analizadas mediante la técnica ELISA) o las variantes LR, RR e YR (datos de LC MS/MS o MALDI-TOF) (Brena, et al., 2021). 
Se calculó la ocurrencia de géneros y especies de cianobacterias desde los primeros registros (1991) hasta 2019, incluyendo informes con datos promediados por períodos de tiempo diversos (Conde, et al., 1999; Chalar, et al., 2010). Se utilizaron los datos del monitoreo visual de cianobacterias (tres categorías, 0: ausencia de cianobacterias, 1: presencia y 2: espuma) para las playas de la ciudad de Mercedes (tramos lóticos), 2017-2020, $n=63$, datos tomados del portal OAN (Uruguay. Ministerio de Medio Ambiente, 2020; Uruguay. Ministerio de Vivienda Ordenamiento Territorial y Medio Ambiente, DINAMA 2019b).

Recientemente, la OMS (Chorus y Welker, 2021) ha propuesto valores guía para varias cianotoxinas (MCs, cylindrospermopsina: CYNs, anatoxinas: ATXs y saxitoxinas: STXs), así como indicadores cuantitativos de cianobacterias y niveles de alerta de agua para potabilización y uso recreativo (ver Tabla 1). En base a dichos criterios, los datos de cianobacterias (indicadores cuantitativos y orientativos: monitoreo visual) se clasificaron en "categorías", definidas en base a los umbrales de peligrosidad de exposición a cianotoxinas según el uso del agua (para potabilizar o para recreación) (Tabla 1). Los datos se clasificaron priorizando el biovolumen, luego las células y por último la concentración de la Clo a. Los niveles visuales, usados para el monitoreo de playas, se clasificaron de forma parsimoniosa asumiendo que el límite para detectar Clo a en el agua por el ojo humano es $\sim 20 \mu \mathrm{gL}^{-1}$ (Tabla 1 ).

A los efectos de resumir los principales cambios en el uso del suelo a lo largo del tiempo, se analizaron las áreas de cobertura de los diferentes usos en la cuenca del Río Negro, para los años 2000, 2008, 2011, 2015 y 2018, ya que a partir de 2000 hay más información limnológica. Se discriminaron seis categorías (agricultura, agua, forestación, herbáceo-arbustivo, monte nativo y otros), donde agricultura incluye también pasturas (FAO y Uruguay. Ministerio de Vivienda Ordenamiento Territorial y Medio Ambiente, 2015; IBGE, 2018). Para 2018 se actualizó la clasificación de 2015 mediante la clasificación de imágenes satelitales (LANDSAT 8 OLI, 2018).

Tabla 1. Indicadores cuantitativos de cianobacterias (Ciano) y niveles de alerta de agua para potabilización y uso recreativo, niveles de monitoreo visual DINAMA y categorías de riesgo de exposición a cianobacterias tóxicas utilizadas en este estudio (Uruguay. Ministerio de Medio Ambiente, DINAMA, 2019b). Valores conservadores: *biovolumen $=0,3 \mathrm{~mm}^{3} \mathrm{~L}^{-1} \mathrm{o} \mathrm{Clo} a=1 \mathrm{\mu gL}^{-1}$ (con predominio de cianobacterias) indica que las MCs o la CYN pueden alcanzar el Valor Guía crónico (de por vida) para estas toxinas en agua potable; **biovolumen $>4$ 
$\mathrm{mm}^{3} \mathrm{~L}^{-1}$ o Clo $a>12 \mathrm{\mu gL}^{-1}$ (con predominio de cianobacterias) indica que las MCs, las CYN o STXs pueden exceder los Valores Guía de exposición de corto plazo para estas toxinas; *** biovolumen $>8 \mathrm{~mm}^{3} \mathrm{~L}^{-1}$ o $\mathrm{Clo} a>24 \mu \mathrm{gL}^{-1}$ (con predominio de cianobacterias) indica que las MCs, las CYN o STXs pueden exceder los Valores Guía de uso recreativo para estas toxinas (Chorus y Welker, 2021).

\begin{tabular}{|c|c|c|c|c|c|c|}
\hline Uso del agua & $\begin{array}{c}\text { Nivel } \\
\text { de alerta } \\
\text { OMS }\end{array}$ & $\begin{array}{l}\text { Biovolumen } \\
\text { Ciano; Clo a }\end{array}$ & $\begin{array}{c}\text { Células } \\
\text { Ciano } \\
\text { (cellsmL-1) }\end{array}$ & $\begin{array}{l}\text { MC-LR } \\
\mu \mathrm{ML}^{-1}\end{array}$ & $\begin{array}{c}\text { Niveles } \\
\text { monitoreo } \\
\text { visual } \\
\text { DINAMA }\end{array}$ & $\begin{array}{l}\text { Categorías } \\
\text { usadas } \\
\text { en este } \\
\text { estudio }\end{array}$ \\
\hline \multirow[t]{3}{*}{ Potabilización } & Vigilancia & $\begin{array}{c}<0,3 \mathrm{~mm}^{3} \mathrm{~L}^{-1} \\
\quad<1 \mu \mathrm{gL}^{-1}\end{array}$ & $<5000$ & $<1 \mu g L^{-1}$ & & 1 (Baja-Nula) \\
\hline & Alerta 1* & $\begin{array}{c}0,3-4 \mathrm{~mm}^{3} \mathrm{~L}^{-1} \\
1-12 \mu \mathrm{gL}^{-1}\end{array}$ & $5000-60000$ & $1-12 \mu g L^{-1 *}$ & & $\begin{array}{c}\mathbf{2} \\
\text { (Baja-Media) }\end{array}$ \\
\hline & Alerta $2^{\star *}$ & $\begin{array}{l}4-8 \mathrm{~mm}^{3} \mathrm{~L}^{-1} \\
12-24 \mu \mathrm{L}^{-1}\end{array}$ & $\begin{array}{l}60000- \\
120000\end{array}$ & $12-24 \mu g L^{-1 \star \star}$ & & $\begin{array}{c}3 \\
\text { (Media-Alta) }\end{array}$ \\
\hline \multirow[t]{3}{*}{ Recreación } & Vigilancia & $\begin{array}{c}1-4 \mathrm{~mm}^{3} \mathrm{~L}^{-1} \\
3-12 \mu \mathrm{L}^{-1}\end{array}$ & & & v0: ausencia & $\begin{array}{c}1-2 \\
\text { (Baja-Media) }\end{array}$ \\
\hline & Alerta 1 & $\begin{array}{l}4-8 \mathrm{~mm}^{3} \mathrm{~L}^{-1} \\
12-24 \mu \mathrm{L}^{-1}\end{array}$ & $\begin{array}{c}<60000- \\
120000\end{array}$ & & v1: presencia & $\begin{array}{c}3 \\
\text { (Media-Alta) }\end{array}$ \\
\hline & Alerta $2 * * *$ & $\begin{array}{l}>8 \mathrm{~mm}^{3} \mathrm{~L}^{-1} ; \\
>24 \mu \mathrm{LL}^{-1}\end{array}$ & $>120000$ & $>24 \mu g^{L^{-1 * * *}}$ & v2: espuma & 4 (Alta) \\
\hline
\end{tabular}

\section{Experimento}

Se realizó un experimento para determinar la influencia de los nutrientes (nitrógeno: $\mathrm{N}$ y fósforo: $\mathrm{P}$ ) y del tiempo de residencia en el crecimiento del fitoplancton. El diseño de tipo factorial incluyó dos factores, nutrientes (Nutr) y tiempo de residencia (Dilu), resultando en cuatro condiciones: control, Nutr, Dilu y Nutr*Dilu. Las variables de respuesta fueron el biovolumen de cianobacterias y eucariotas, y las microcistinas totales.

Se utilizó una muestra subsuperficial de $20 \mathrm{~L}$ del embalse Palmar (27/06/2014) (Figura 1, sitio 12), que se trasladó en oscuridad y a baja temperatura al laboratorio de la Sección Limnología, en la Facultad de Ciencias (Montevideo), donde se determinó la concentración de nutrientes según Valderrama (1981) (98 $\pm 5,8 \mu \mathrm{gPT} \mathrm{L}^{-1}$ y $0,75 \pm 0,09 \mathrm{mgNT} \mathrm{L}^{-1}, \mathrm{~N}$ y $\mathrm{P}$, respectivamente). La muestra fue homogeneizada y se distribuyeron $600 \mathrm{~mL}$ en frascos de vidrio de $1 \mathrm{~L}$. Para el factor Nutr se usó nitrato $\left(\mathrm{NaNO}_{3}\right)$ y fosfato $\left(\mathrm{K}_{2} \mathrm{HPO}_{4}\right)$. Las soluciones de 
nutrientes fueron dosificadas en pulsos diarios (9 adiciones, una por cada día del experimento, excepto el último). La dosis diaria fue de $133 \mu \mathrm{gL}^{-1}$ y $1,02 \mathrm{mgL}^{-1}$ (fosfato y nitrato, respectivamente), totalizando $1,1 \mathrm{mgL}^{-1}$ y $8,2 \mathrm{mgL}^{-1}, \mathrm{P}$ y N respectivamente. El tiempo de residencia bajo ( 3,4 días) se emuló por dilución, realizando un recambio diario de $175 \mathrm{~mL}$ con agua de río filtrada (filtro MGF, Munktell, Alemania). El tiempo de residencia alto representó los 10 días del experimento (sin dilución). Para el tratamiento combinado, Nutr*Dilu, la dilución diaria fue anterior al agregado de nutrientes. Las réplicas $(n=3)$ se aclimataron 40 horas a $25 \pm 2{ }^{\circ} \mathrm{C}, 110-115 \mu \mathrm{mol}$ fotón $\mathrm{m}^{-2} \mathrm{~s}^{-1}$ y fotoperíodo 16:8, luz:oscuridad y se ordenaron al azar. Durante los 10 días de incubación se siguieron los cambios de la fluorescencia in vivo de la Clo a y la ficocianina (Cremella, et al., 2018) para calcular la tasa de crecimiento (en día ${ }^{-1}$ ). Al finalizar (10 días), parte de las muestras se fijaron con solución lugol para el conteo de fitoplancton, y el resto se congeló para el análisis de $M C$ totales mediante la técnica ELISA (Brena, et al., 2021). La identificación y conteo del fitoplancton se realizó para cada unidad experimental, según métodos de rutina descritos en Illarze (2015). Las diferencias significativas entre tratamientos se probaron mediante ANOVA de una vía y una prueba de comparaciones pareadas posterior (con distancia de Holmes), verificando previamente la normalidad y homogeneidad de varianza de los datos.

Todas las gráficas y los análisis estadísticos fueron realizados con el programa libre R (3.5.3).

\section{RESULTADOS}

\section{Datos históricos}

Los estudios de cianobacterias en el Río Negro comenzaron en la década de los noventa (trabajos de la Sección Limnología, incluyendo pocos datos de 1989) y continuaron a lo largo del tiempo en forma dispar. El sitio más estudiado ha sido $B O(n=111)$ y los menos estudiados han sido los tramos lóticos del río (aguas arriba, entre y aguas abajo de los embalses) ( $n=26$, excluyendo los monitoreos visuales). Se registraron 21 géneros de cianobacterias entre 1991 y 2018, de los cuales el 57\% pertenece a organismos filamentosos. El género Dolichospermum (orden Nostocales) fue el más frecuente, seguido de Microcystis, Merismopedia, Pseudanabaena y Radiocystis (Figura 2).

Los primeros datos cuantitativos corresponden a la concentración de Clo a e individuos por litro (variable que no es indicadora de biomasa ni abundancia). 
Posteriormente se incorporaron las estimaciones de abundancia de cianobacterias en células (a partir del 2000) y en biovolumen (Tabla 2). El mayor número de registros con información cuantitativa de cianobacterias corresponde a los embalses a partir de $2010(n=187)$ (Tabla 2). Los valores mayores a 500 $\mu \mathrm{LL}^{-1}$ de Clo a y de $100 \mathrm{~mm}^{3} \mathrm{~L}^{-1}$ de biovolumen son de densas acumulaciones de biomasa de cianobacteria ("espuma"), condiciones alcanzadas en los tres embalses (Tabla 2).

Las categorías de peligrosidad de exposición a cianobacterias tóxicas (Tabla 1) permitieron evidenciar una tendencia al aumento de casos en las categorías de peligrosidad media a alta desde 1989 a 2015 (Figura 3). Desde 2017 se registraron valores que corresponden a la categoría 1-2 para aguas recreacionales, y se observó un aumento de los registros en la categoría 3 (Media-Alta) (Figura 3). Tanto en los embalses como en los tramos lóticos (entre embalses o aguas abajo de los mismos), se han reportado cianobacterias con niveles de peligrosidad altos para ambos usos del agua (categorías 3 y 4). En los tramos lóticos posteriores a BO, el biovolumen y las células de cianobacterias son generalmente un orden de magnitud más bajos que en los embalses (Tabla 2). Antes del 2010 sólo se registró un sitio lótico (desembocadura del Río Yi, enero 2001) con información de cianobacterias (Figura 3), y ninguno en el río aguas arriba de los embalses.

Las únicas toxinas que han sido analizadas en el Río Negro son las microcistinas, en general como totales, aunque hay reportes con algunas variantes químicas (Tabla 2). La información disponible apenas supera los 60 registros (MC totales y variante $L R$ ), donde el $23 \%$ de los datos de la zona pelágica y el $58 \%$ de la orilla superan los $24 \mathrm{\mu gL}^{-1}$ (Alerta 2, peligrosidad alta para aguas de recreación, OMS, Tabla 1). Los primeros informes de cianotoxinas correspondieron a floraciones de Microcystis aeruginosa y Dolichospermum circinale en BO (MC totales: 909 y 551 mggp.s. $^{-1}$, sitios Carpintería y Represa, respectivamente; diciembre/2000) y en los tres embalses al verano siguiente (enero/2001) (MC totales: 763; 701 y 971 gggp.s. $^{-1}$ en BA, BO y PA, respectivamente y un valor casi cuatro veces más alto en el tramo lótico) (Tabla 2). La variante química de $M C$ más analizada ha sido la $L R$, pero se han cuantificado puntualmente las MCs-RR (sitios 5 y 6) e YR (sitio 5) (Figura 1, Tabla $2)$, en presencia de una floración dominada por las cianobacterias coloniales Radiocystis fernandoii y Microcystis wesenbergii (cianobacterias totales: 1.375; 38 y $40 \mathrm{~mm}^{3} \mathrm{~L}^{-1}$, sitios 5, 6 y 7, respectivamente, noviembre/2014). 


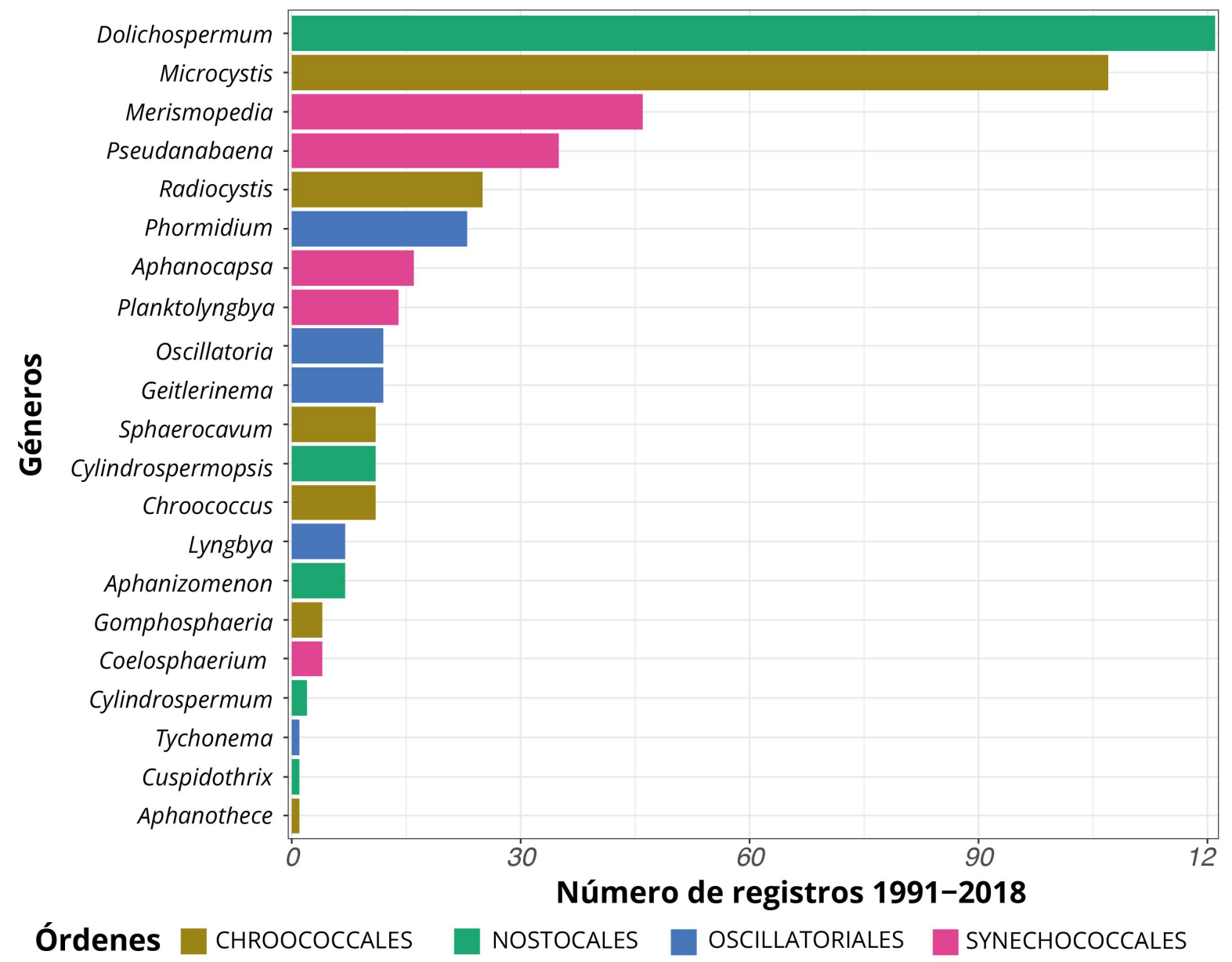

Figura 2. Registro de géneros de cianobacterias en los tres embalses del Río Negro. Los colores indican los cuatro órdenes filogenéticos.

Tabla 2. Biovolumen de cianobacterias (2010-2015) y microcistinas (MC), (20002001 y 2010-2015) registrados en el Río Negro, tramos lóticos (rn), embalses (Bonete, Baygorria y Palmar) y todos los datos (Todos). Se indica la mediana, el rango (mínimo-máximo, entre paréntesis rectos) y el $n$ (cursiva); *: $n=1$, nd: analizado y no detectado. Los datos de biovolumen se discriminan según la muestra haya sido tomada en la orilla o en la zona pelágica (centro). Métodos: ELISA (MC_totales) o LC MS/MS o MALDITOF para las variantes; a: río Yi (2000). Referencias (Ref): 1) De León, et al., 2001, 2) Conde, et al., 2002, 3) GonzálezPiana, et al., 2011, 4) González-Piana, et al., 2017, 5) Brena, et al., 2021 y 6) este estudio. 


\begin{tabular}{|c|c|c|c|c|c|c|}
\hline $\begin{array}{c}\text { Biovolumen } \\
\text { o Toxinas }\end{array}$ & Bonete & Baygorria & Palmar & rn & Todos & Ref \\
\hline $\begin{array}{l}\text { Cianobacterias } \\
\left(\mathrm{mm}^{3} \mathrm{~L}^{-1}\right) \text {, centro }\end{array}$ & $\begin{array}{c}0,537 \\
{[0-1370], 99}\end{array}$ & $\begin{array}{l}0,288[0- \\
25,6], 75\end{array}$ & $\begin{array}{c}1,69[0- \\
48,7], 76\end{array}$ & $\begin{array}{c}0,0236 \\
{[0,00243-} \\
40,2], 19\end{array}$ & $\begin{array}{c}0,545 \\
{[0-1370]}\end{array}$ & $3 ; 4 ; 6$ \\
\hline $\begin{array}{l}\text { Cianobacterias } \\
\left(\mathrm{mm}^{3} \mathrm{~L}^{-1}\right) \text {, orilla }\end{array}$ & $\begin{array}{c}10,4 \\
{[0,0300-1660], 8}\end{array}$ & $\begin{array}{l}992[27,0- \\
15300], 9\end{array}$ & $\begin{array}{c}0,510 \\
{[0,410-} \\
18,9], 5\end{array}$ & - & $\begin{array}{c}76,2 \\
{[0,0300-} \\
15300]\end{array}$ & $3 ; 5 ; 6$ \\
\hline $\begin{array}{c}\text { MC_totales } \\
\left(\mu \mathrm{L}^{-1}\right)\end{array}$ & $\begin{array}{c}8,80 \\
{[0,610-1250], 7}\end{array}$ & $\begin{array}{r}32,0[0,793- \\
\left.3 \times 10^{4}\right], 13\end{array}$ & $\begin{array}{c}21,2[2,79- \\
3440], 4\end{array}$ & $\begin{array}{c}0 \\
{[0-23,9], 22}\end{array}$ & $\begin{array}{c}2,95 \\
{\left[0-3 \times 10^{4}\right]}\end{array}$ & $4 ; 5$ \\
\hline$M C_{-} L R\left(\mu \mathrm{gL}^{-1}\right)$ & $\begin{array}{c}151 \\
{[3,80-2110], 4}\end{array}$ & $\begin{array}{c}33,0 \\
{[26,6-551], 3}\end{array}$ & $\begin{array}{c}34,0[2,29- \\
2660], 7\end{array}$ & 1,80 * & $\begin{array}{c}33,0 \\
{[1,80-} \\
2660]\end{array}$ & $3 ; 4 ; 6$ \\
\hline$M C_{-} R R\left(\mu g L^{-1}\right)$ & $23,6 *$ & nd & nd & $5,60 *$ & - & 6 \\
\hline$M C_{-} Y R\left(\mu g L^{-1}\right)$ & $3,60 *$ & nd & nd & nd & - & 6 \\
\hline $\begin{array}{l}\text { MC_totales } \\
\left(\mu \text { ggp.s. }^{-1}\right)\end{array}$ & $\begin{array}{c}763 \\
{[627-899], 2}\end{array}$ & $\begin{array}{c}673 \\
{[551-909], 4}\end{array}$ & $\begin{array}{c}957 \\
{[886-1030], 2}\end{array}$ & $2880 * a$ & $\begin{array}{c}886 \\
{[551-2880]}\end{array}$ & $1 ; 2$ \\
\hline $\begin{array}{l}\text { MC_totales/ } \\
\text { peso fresco } \\
\left(\mu \mathrm{gmm}^{-3}\right)\end{array}$ & $\begin{array}{c}0,174 \\
{[0,02-9,98], 5}\end{array}$ & $\begin{array}{c}0,076 \\
{[0,005-0,59], 8}\end{array}$ & - & $\begin{array}{c}0 \\
{[0-0,41], 10}\end{array}$ & $\begin{array}{c}0,09 \\
{[0,01-9,98]}\end{array}$ & $6 ; 5$ \\
\hline $\begin{array}{l}\text { MC_LR/ peso } \\
\text { fresco }\left(\mu \mathrm{gmm}^{-3}\right)\end{array}$ & $\begin{array}{c}0,486 \\
{[0,01-3,81], 11}\end{array}$ & $\begin{array}{c}2,154 \\
{[0,55-9,85], 6}\end{array}$ & $\begin{array}{c}0,96 \\
{[0,118-87,6], 11}\end{array}$ & - & $\begin{array}{c}0,69 \\
{[0,01-87,6]}\end{array}$ & $4 ; 6$ \\
\hline
\end{tabular}

El PT en el agua presentó valores altos, por encima de los umbrales de condición eutrófica a lo largo de todo el período, tanto para embalses (excepto en 2000) como para los tramos lóticos (Figura 4). EI NT presentó concentraciones muy altas con una tendencia general al aumento en los cuantiles superiores $(0,90)$ desde 2000 a 2018 (Figura 4). El uso del suelo de la cuenca del Río Negro tuvo cambios importantes entre 2000 y 2018. Se incrementó el porcentaje de área cubierta de la cuenca destinada a la agricultura (15 al 23\%) y la forestación (6 a 11\%) en los años 2000 y 2018, respectivamente (Figura 4). Este cambio determinó una disminución de 960.870 hectáreas ocupadas por la cobertura herbáceo-arbustiva (del 73 al 59\% del área total de la cuenca, en 2000 y 2018 respectivamente). 
A Todos los datos

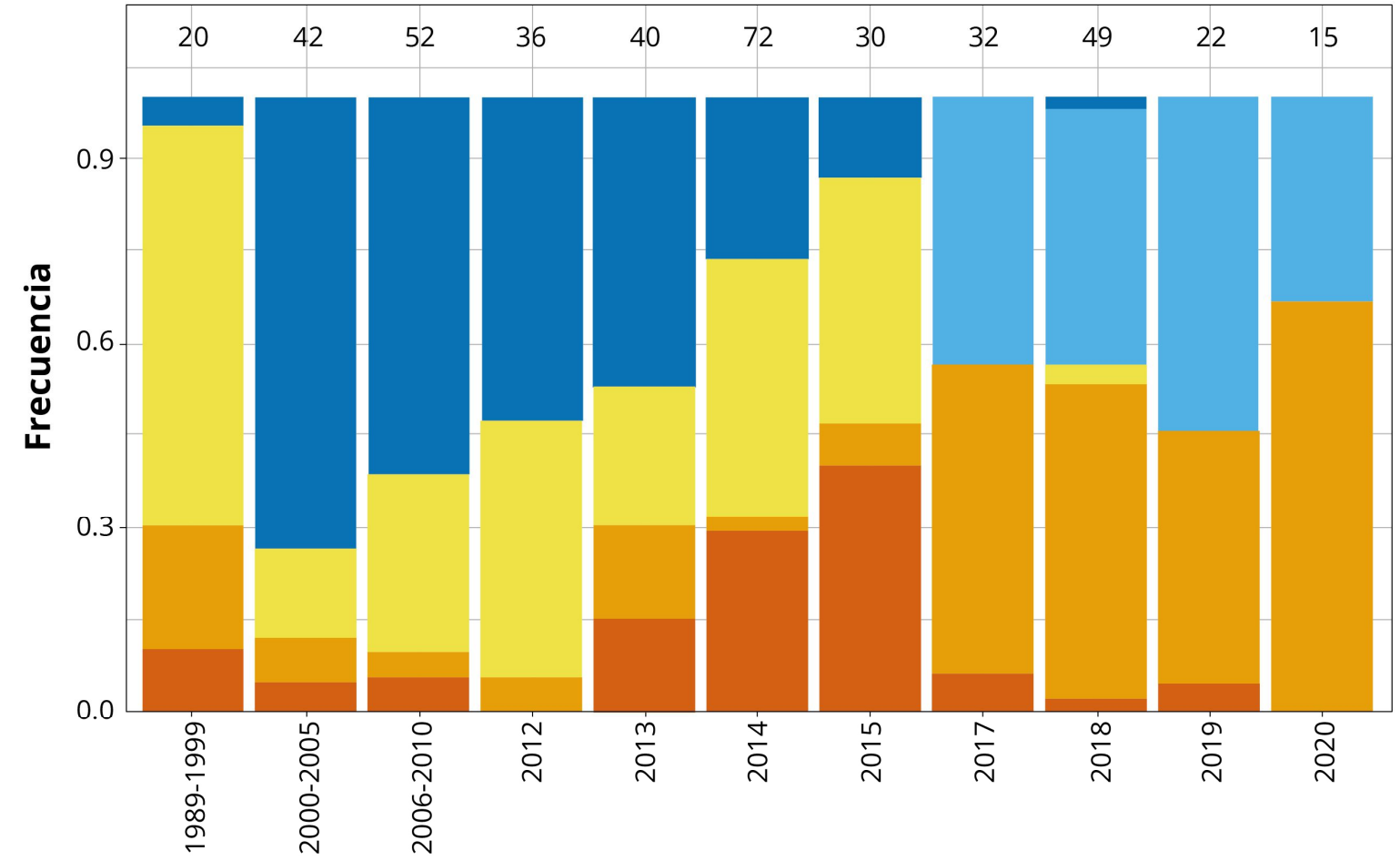

Año

B

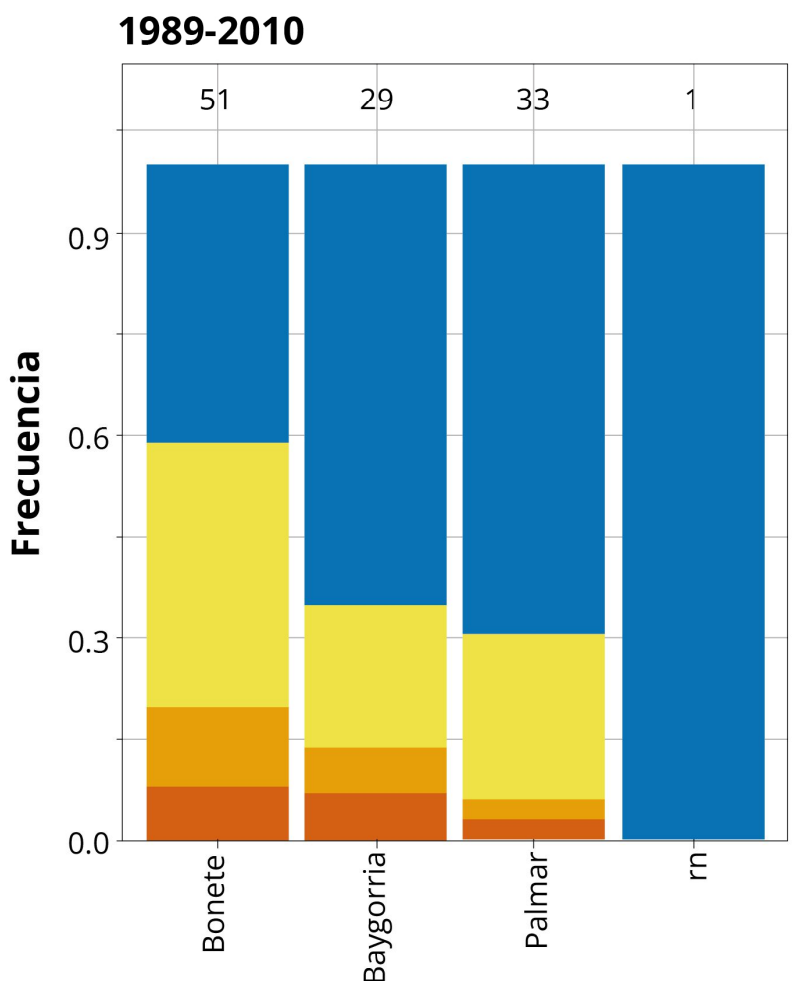

Sitios
C

\section{1-2020}

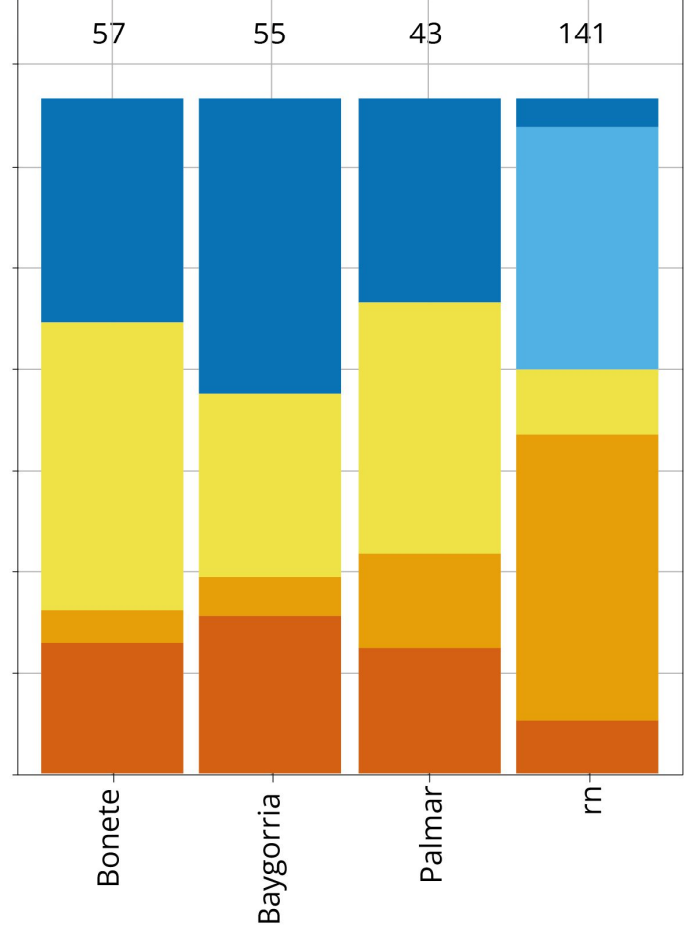

Sitios 
Figura 3. Frecuencia de registro de floraciones en categorías de peligrosidad de exposición a cianobacterias tóxicas (ver Tabla 1). A: para todos los datos a lo largo del tiempo. Agrupado por embalses (Bonete, Baygorria y Palmar) y tramos lóticos (rn), para dos períodos, B: 1989-2010 y C: 2011-2020. $n$ = número de datos, indicado arriba de cada barra.

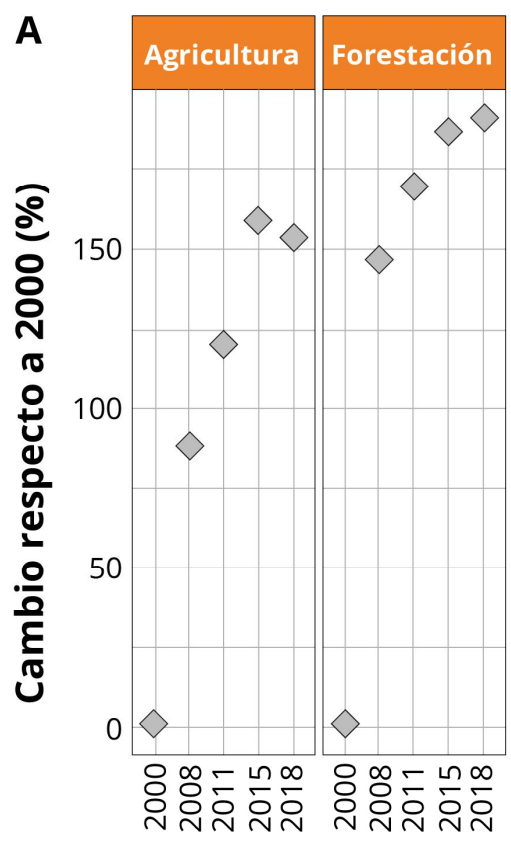

Años

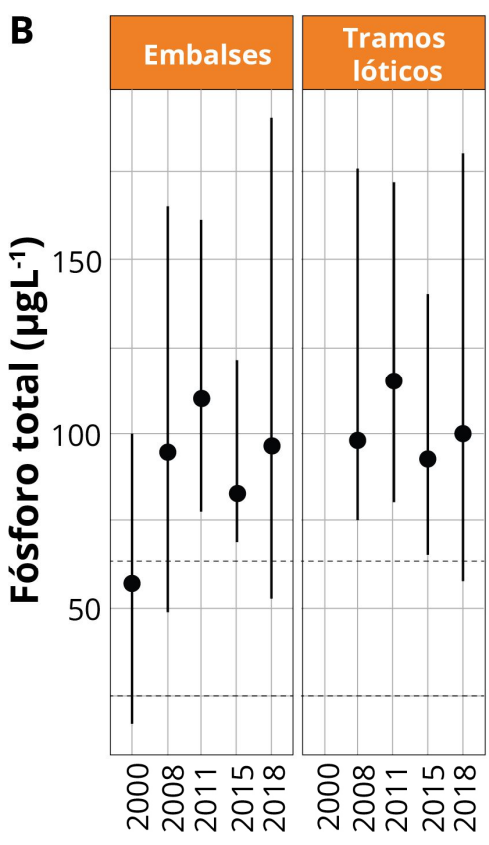

Años

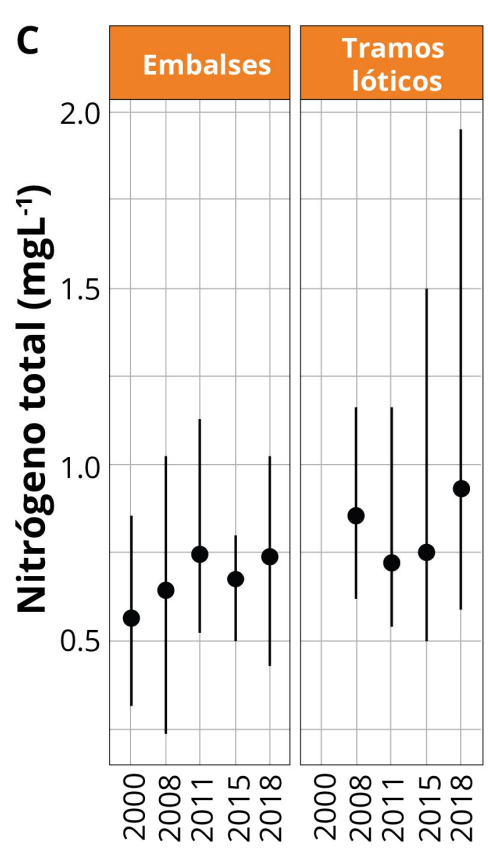

Años

Figura 4. A: Cambio del uso del suelo (\%) respecto al 2000 para agricultura y forestación. B: Variación de la concentración de fósforo total y C: Variación de la concentración de nitrógeno total, desde 2000 a 2018, según embalses y tramos lóticos. Se indica la mediana (círculo negro, y los cuantiles 0,10/0,90). En B las líneas horizontales punteadas: 25 y 63,7 $\mathrm{\mu gL}^{-1}$ de fósforo total (umbral en la legislación uruguaya y máxima para el estado eutrófico para embalses subtropicales según Cunha, et al., 2013, respectivamente).

\section{Experimento de nutrientes y tiempo de residencia}

El agregado de nutrientes resultó en un aumento significativo del biovolumen de cianobacterias y de las MCs (Figura 5). Las cianobacterias fueron el grupo dominante en el fitoplancton ( $>90 \%$ del biovolumen total, género dominante: Microcystis), tanto en el control como en los dos tratamientos con adición de nutrientes (Nutr y Nutr*Dilu). El biovolumen de cianobacterias del tratamiento Nutr fue, en promedio, 7 veces más alto que en el control (2.918 y $412 \mathrm{~mm}^{3} \mathrm{~L}^{-1}$, Nutr y control, respectivamente). El tratamiento Dilu presentó una mayor 
diversidad de grupos eucariotas de pequeño tamaño individual y muy baja contribución de cianobacterias ( 3\% del total), siendo 3 órdenes de magnitud menor al del control (Figura 5). Finalmente, el tratamiento Nutr*Dilu alcanzó biovolúmenes de cianobacterias altos pero menores al control (promedio: 206 $\mathrm{mm}^{3} \mathrm{~L}^{-1}$ ). Con adición de nutrientes se observaron los mayores crecimientos (0,204 y 0,153 día ${ }^{-1}$, Nutr y Nutr*Dilu, respectivamente), mientras que los otros tratamientos presentaron una tasa de crecimiento muy baja $\left(0,069\right.$ y 0,003 día ${ }^{-1}$, Dilu y control, respectivamente). La concentración de MCs fue significativamente más alta en Nutr que en el resto de los tratamientos (Figura 5). Sin embargo, las MCs expresadas por unidad de biomasa fueron bajas en los tratamientos con adición de nutrientes $\left(0,012 \pm 0,005 \mu^{2} \mathrm{gmm}^{-3}\right.$ y 0,012 $\pm 0,014 \mu \mathrm{gmm}^{-3}$, Nutr y Nutr*Dilu, respectivamente) y más altas en los restantes $\left(0,029 \pm 0,025 \mu \mathrm{gmm}^{-3} \mathrm{y}\right.$

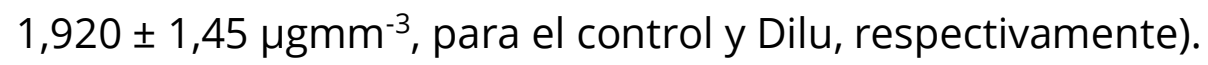

A

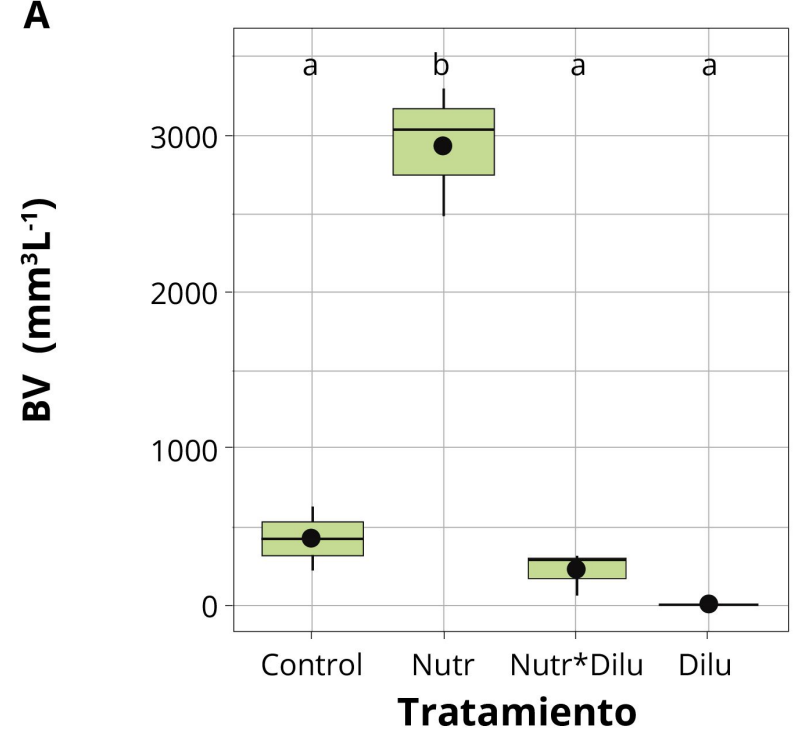

C

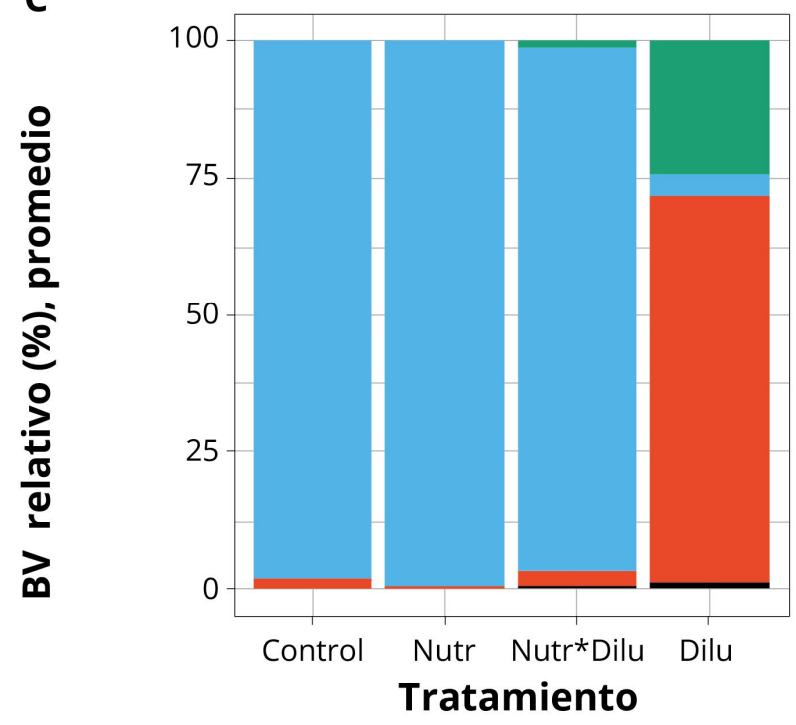

B

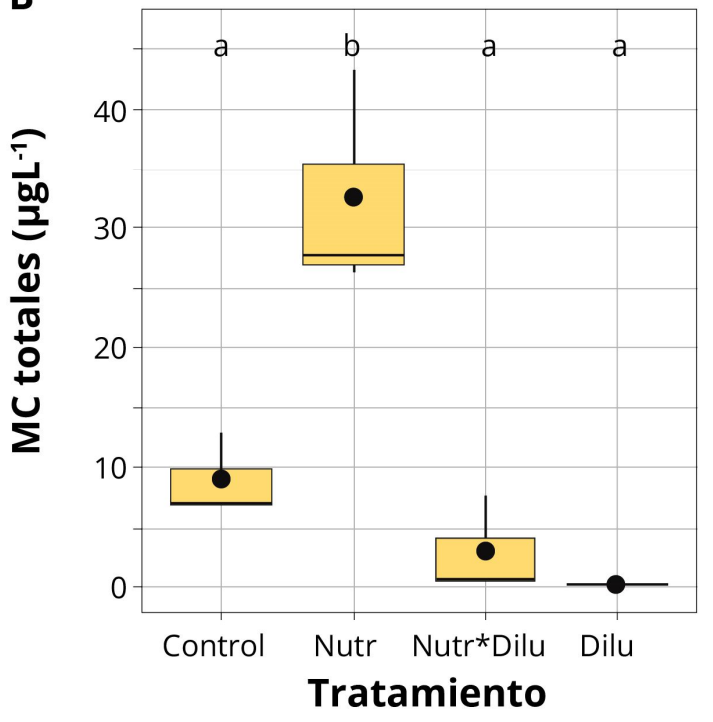


Figura 5. Experimento de enriquecimiento con nutrientes y dilución en muestras naturales de PA Control (sin enriquecimiento ni dilución), Dilu: dilución diaria, Nutr: agregado de N+P, Nutr*Dilu: ambos factores combinados. A: biovolumen total de fitoplancton, B: microcistinas totales (MC), y C: contribución relativa de los diferentes grupos en el total del biovolumen. Las letras indican diferencias significativas entre tratamientos $(p<0,05)$. Para cada tratamiento $n=3$.

\section{DISCUSIÓN}

Nuestro estudio permitió evidenciar la situación del Río Negro en relación con la presencia de floraciones de cianobacterias tóxicas en las últimas décadas. La tendencia temporal muestra un aumento de casos de categorías que indican peligrosidad media a alta de exposición a cianotoxinas, algunas que no han sido estudiadas aún en el país, lo que representa un alto riesgo para el uso del agua con diferentes fines.

\section{Tendencias temporales de la biomasa y toxinas de cianobacterias, y el uso del suelo en el Río Negro}

La mayoría de las floraciones estuvieron dominadas por Dolichospermum y Microcystis (o Radiocystis), las cianobacterias más frecuentes en los cuerpos de agua lénticos y lóticos eutróficos del país (Bonilla, et al., 2015; Ferrari, et al., 2011; Haakonsson, et al., 2017). Estos taxa son potencialmente tóxicos, y pueden producir lipopolisacáridos (dermatotoxinas), microcistinas (hepatotoxinas) y potentes neurotoxinas (saxitoxina, anatoxina-a y anatoxina-a(S)) (van Apeldoorn, et al., 2007; Furtado, et al., 2009). La mayoría de las neurotoxinas no se analizan en parte por limitaciones en la capacidad analítica del país, por lo que puede existir un riesgo ambiental y sanitario que aún no ha sido identificado apropiadamente.

Las concentraciones de cianobacterias (células y biovolumen) compiladas en nuestro trabajo indican condiciones eutróficas a hipereutróficas (Chorus y Welker, 2021), particularmente en los embalses. La mayoría de los estudios corresponden al período estival, aunque floraciones de cianobacterias también han sido registradas en otoño-invierno en los embalses (Chalar, et al., 2010, 2014), por lo que la problemática se extiende a períodos fríos, generalmente indicados como poco favorables para las floraciones. Si bien el conocimiento de las cianobacterias en los tramos lóticos del río es muy limitada y fragmentada, no se han registrado en la cuenca alta (antes de los embalses) (Pérez, 2002 y datos de este estudio). Por otro lado, las cianobacterias circulan por el río a 
partir del embalse $\mathrm{BO}$, mediado por las precipitaciones y el manejo de los embalses, y son transportadas a PA, donde ocurre el aumento de la biomasa y su posterior descarga hacia el río Uruguay, e incluso a cientos de kilómetros de distancia como el Río de la Plata y Océano Atlántico (Kruk, et al., 2019; Aubriot, et al., 2020).

Las concentraciones de microcistinas alcanzaron valores extremadamente altos en muestras provenientes de espuma de cianobacterias, señalando una elevada peligrosidad para bañistas, pescadores y animales domésticos. Recientemente se han detectado MCs en la sangre de ganado que abrevaba en el Río Negro (BO y BA) con presencia de floraciones (Brena, et al., 2021), lo que podría derivar en un perjuicio económico directo para la ganadería y la salud animal. En cuanto a las variantes químicas encontradas en el agua, la LR fue la reportada con mayor frecuencia, en línea con estudios anteriores (Brena, et al., 2021). En este estudio, los valores promedio de MC por biovolumen (peso fresco) indican toxicidad media (valores promedios para MC totales y LR: 0,024 - 3,25 uggp.s. ${ }^{-1}$, asumiendo $1 \mathrm{~mm}^{3}=0,25$ p.s.) respecto a los rangos encontrados en la literatura (máximos $~ 9$ Mggp.s. ${ }^{-1}$ ) (Chorus y Welker, 2021). Sin embargo, los primeros reportes conocidos (2001) tienen valores cercanos a 1 mggp.s. $^{-1}$ (De León, et al., 2001), lo que puede deberse al análisis de espumas cianobacterianas. Los valores y las tendencias de MCs comprometen el uso del agua en general e indican la necesidad de incrementar los monitoreos de estos organismos. Diversos métodos, de alta frecuencia y de bajos costos, pueden proporcionar información orientativa o semi-cuantitativa en tiempo real, como el monitoreo visual en zonas de recreación de la ciudad de Mercedes (sitio 15, Figura 1) (Uruguay. Ministerio de Vivienda Ordenamiento Territorial y Medio Ambiente; DINAMA, 2019b), el monitoreo remoto o la medición de la fluorescencia de pigmentos in vivo (Cremella, et al., 2018; Aubriot, et al., 2020).

Los valores de nutrientes totales registrados en el Río Negro (2000-2018) indican condiciones eutróficas a hipereutróficas (valores de fósforo total $>63,7$ $\mu L^{-1}$, Cunha, et al., 2013). Dichas concentraciones son mayores a los promedios históricos del río Uruguay y algo menores a los del río Santa Lucía, ecosistemas lóticos del país fuertemente impactados (Aubriot, et al., 2017; Alonso, et al., 2019). Los valores de fósforo total registrados en este estudio fueron entre 2 y 18 veces mayores que el permitido por la legislación uruguaya $\left(25 \mu \mathrm{L}^{-1}\right.$, excepto para la Clase 4), Decreto 253/979 (Uruguay, 1979). Esto, junto a los índices de estado trófico, indican un grado de deterioro muy importante en la calidad del agua. Las concentraciones de nitrógeno total fueron altas y con una tendencia en ascenso desde 2000 a 2018, lo que puede estar relacionado al aumento de la 
agricultura en la cuenca y la tendencia mundial a usar fertilizantes nitrogenados (Glibert, et al., 2014).

El aumento en la agricultura varía según regiones de la cuenca, siendo más importante en el Este que en el Centro y Oeste (100\% y 10-50\%, Este, y Centro y Oeste, respectivamente, período 2011-2015) (Uruguay. Ministerio de Vivienda Ordenamiento Territorial y Medio Ambiente; DINAMA, 2018), asociado a la expansión de monocultivos de soja y forestación (Gazzano, et al., 2019). Las cargas de PT y NT aportadas por los cultivos han sido estimadas en $50 \%$ de la carga total en la región Este y Centro (cuenca alta y media), y en más del $80 \%$ en cuenca media a baja (Uruguay. Ministerio de Vivienda Ordenamiento Territorial y Medio Ambiente; DINAMA, 2018). Considerando que las fuentes puntuales de PT y NT son relativamente bajas en esta cuenca $(1,2 \%$ y $2,2 \%$, PT y NT, respectivamente, para 2015-2016) (Uruguay. Ministerio de Vivienda Ordenamiento Territorial y Medio Ambiente, DINAMA, 2018), emprendimientos industriales de gran porte (ejemplo: UPM II, planta de pasta de celulosa) pueden alterar esta tendencia. Se estima que esta planta volcará al río aproximadamente 38 y 168 Ton.año-1 de PT y NT, respectivamente, al inicio de su funcionamiento (Uruguay. Ministerio de Vivienda Ordenamiento Territorial y Medio Ambiente, DINAMA, 2019a). Modelaciones realizadas por DINAMA indican que la frecuencia de floraciones algales se incrementaría, al menos en BA, en períodos de bajo caudal $\left(<65 \mathrm{~m}^{3} \mathrm{~s}^{-1}\right)$ (Uruguay. Ministerio de Vivienda Ordenamiento Territorial y Medio Ambiente, DINAMA, 2019a). Sin embargo, se desconocen los efectos que podría tener la descarga de UPM II aguas abajo (embalse PA). Las cargas de nutrientes aportadas por UPM II en períodos de bajos caudales y en períodos cálidos (alta temperatura y luz) podrían generar un impacto significativo en el aumento de la frecuencia y persistencia de floraciones de cianobacterias. Estas variaciones además estarán regidas por el régimen de precipitaciones que afectará al caudal.

\section{Efectos de los nutrientes y el tiempo de residencia en la biomasa y las microcistinas}

Nuestros resultados experimentales evidenciaron el efecto combinado de los nutrientes y el tiempo de residencia del agua en la acumulación de altas biomasas de cianobacterias. La muestra natural de PA utilizada tenía características eutróficas (ver Materiales y Métodos), pero aun así el agregado de nutrientes generó un aumento del biovolumen de fitoplancton 7 veces mayor al control, con dominancia de cianobacterias tóxicas. Esto implica que, bajo condiciones apropiadas de temperatura y luz, un aumento de aportes de nutrientes puede derivar en un agravamiento de la situación en el ecosistema 
(Maavara, et al., 2015). Las altas concentraciones de cianobacterias estuvieron acompañadas de un aumento de la concentración de MC totales, indicando alta peligrosidad de exposición para humanos (Chorus y Welker, 2021). En los tratamientos con dilución, que emulan las condiciones lóticas, la baja biomasa se explica por la acción del lavado diario; por lo tanto, se demostró el papel clave de las condiciones lénticas en la formación de las floraciones de cianobacterias. El tiempo de residencia del agua del río ( $\sim$ horas a pocos días) es mayor al tiempo de crecimiento fitoplanctónico ( $3 \mathrm{día}^{-1}$ en condiciones naturales) (Huisman, et al., 2018), lo que limita la acumulación de biomasa de cianobacterias de gran tamaño individual. Sin embargo, el represamiento de los ríos aumenta el tiempo de residencia, permitiendo entonces el crecimiento y la acumulación de biomasa (Davis y Koop, 2006). El lavado de dicha biomasa depende del manejo de los embalses, pero también del régimen de precipitaciones afectadas por el evento de escala regional El Niño/a Oscilación del Sur (ENSO, por sus siglas en inglés), muchas veces generando situaciones complejas o imposibles de controlar (Aubriot, et al., 2020). Los pronósticos de cambio climático para la región incluyen aumentos en la frecuencia de fenómenos de precipitaciones extremos (sequías y lluvias), lo que puede influir de forma significativa en el fenómeno de las floraciones (Haakonsson, et al., 2017).

\section{Implicancias de las floraciones tóxicas para el uso del agua con fines múltiples}

La cuenca del Río Negro se ha visto afectada por un aumento de actividades productivas, lo que se refleja en los valores y las tendencias de los resultados de nuestro estudio. El aumento de la frecuencia y severidad de las floraciones tóxicas en los embalses en la última década alerta sobre la situación crítica del Río Negro y las posibles consecuencias en los servicios ecosistémicos que ofrece (Figura 6). La eutrofización de los ecosistemas límnicos en Uruguay data de varias décadas (Conde y Sommaruga, 1999; Bonilla, et al., 2015; Aubriot, et al., 2017; Goyenola, et al., 2021), y está asociada al aporte de fuentes difusas como la agricultura, de fuentes puntuales (por ejemplo, lechería, frigoríficos) y de aportes urbanos sin tratamientos adecuados de los efluentes (Barreto, et al., 2017; Chalar, et al., 2017; Arocena, et al., 2018). Las predicciones de cambio climático pronostican un aumento de eventos meteorológicos extremos que modificarán la circulación del agua y el aporte de nutrientes desde la cuenca, actuando en sinergia con la eutrofización (Figura 6) y favoreciendo las floraciones (Paerl, 2017; Haakonsson, et al., 2017). Las pérdidas económicas derivadas de los efectos de la eutrofización pueden llegar a ser muy elevadas (Dodds, et al., 2009), por lo que son imprescindibles los planes de manejo tendientes a reducir el aporte de nutrientes al agua (Steffensen, 2008; Sinha, et al., 2019; Goyenola, et al., 2021) para revertir la situación en el río. 


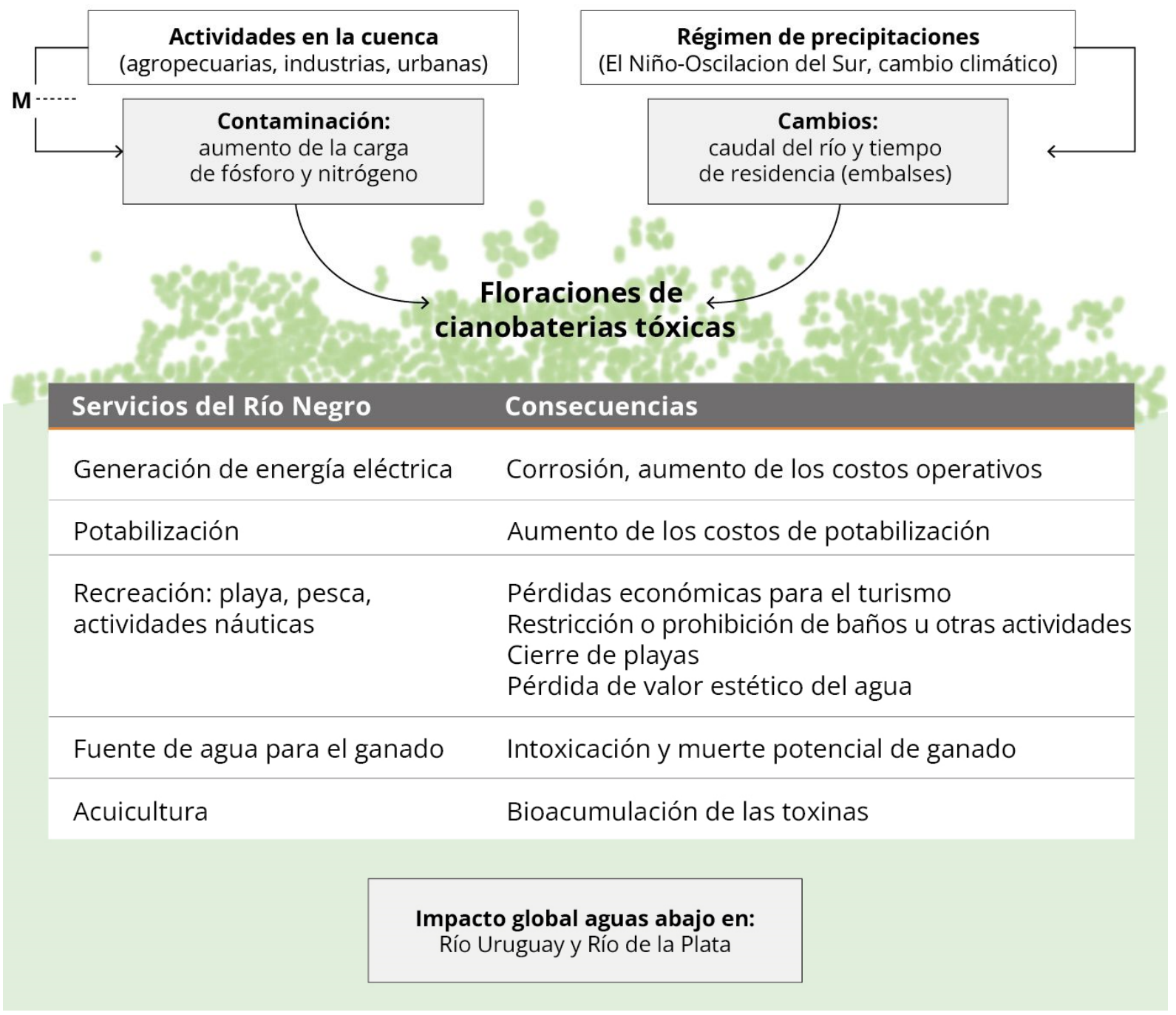

Figura 6. Principales causas de las floraciones de cianobacterias tóxicas (cajas blancas), los efectos en el agua (cajas grises) y las consecuencias en los servicios que brinda el río (cuadro inferior). La línea punteada indica donde se deberían tomar acciones de manejo (M) para disminuir el aporte de nutrientes.

\section{CONCLUSIONES}

Mediante la integración de la información histórica de campo y los resultados experimentales, nuestro estudio logró poner en evidencia la gravedad de la situación actual de la eutrofización del Río Negro. Las floraciones de cianobacterias tóxicas representan un riesgo elevado para la salud humana y animal, y para otros servicios ecosistémicos. Nuestros resultados alertan que la situación puede empeorar, agravada por el efecto del cambio climático. Esto derivaría en consecuencias negativas para la sociedad y la economía si no se 
toman medidas que reviertan la tendencia actual. Es necesario contar con más estudios experimentales que permitan identificar la causalidad e intensificar la frecuencia de los monitoreos ambientales, incluyendo la medición de las cianobacterias (análisis taxonómico, cuantificación de biomasa, observación visual, pigmentos in vivo, y teledetección) y de las toxinas. El trabajo conjunto entre la academia y los tomadores de decisión es esencial para lograr una gestión adecuada a largo plazo que permita revertir la situación actual y asegure el desarrollo sostenible del Río Negro.

\section{AGRADECIMIENTOS}

Este trabajo fue parcialmente financiado por ANII (FCE-6384) y DINAMA (Convenios 2013-2016 y 2020). Parte de los resultados son de la Tesis de Licenciatura en Ciencias Biológicas de M. Illarze. A M. C. Pérez, B. Cremella, A. Somma y E. Font por la asistencia técnica en campo y laboratorio; y a C. Leite Sant'Anna por las correcciones del portugués.

\section{REFERENCIAS}

Alonso, J., Quintans, F., Taks, J., Conde, D., Chalar, G., Bonilla, S., et. al., 2019. Water Quality in Uruguay: Current status and challenges. En: Water Quality in the Americas. Risks and Opportunities. Mexico: IANAS, pp.561-597.

Arocena, R., Chalar, G. y Pacheco, J.P., 2018. Agriculture and elevation are the main factors for Pampasic stream habitat and water quality. En: Environmental Monitoring and Assessment, 190, 254. DOI: https://doi.org/10.1007/s10661-018$\underline{6622-6}$

Aubriot, L., Zabaleta, B., Bordet, F., Sienra, D., Risso, J., Achkar, M. y Somma, A., 2020. Assessing the origin of a massive cyanobacterial bloom in the Río de la Plata (2019): Towards an early warning system. En: Water Research, 181, pp.115944. DOI: https://doi.org/10.1016/j.watres.2020.115944

Aubriot, L.E., Delbene, L., Haakonsson, S., Somma, A., Hirsch, F. y Bonilla, S., 2017. Evolución de la eutrofización en el Río Santa Lucía: influencia de la intensificación productiva y perspectivas. En: INNOTEC, 14, pp.7-16. DOI:

https://doi.org/10.26461/14.04

Barreto, P., Dogliotti, S. y Perdomo, C., 2017. Surface water quality of intensive farming areas within the Santa Lucia River basin of Uruguay. En: Air, Soil and Water Research, 10, pp.1-8. DOI: https://doi.org/10.1177/1178622117715446. 
Bonilla, S., Haakonsson, S., Somma, A., Gravier, A., Britos, A., Vidal, L., De León, L., Brena, B., Pírez, M., Piccini, C., Martínez de la Escalera, G., Chalar, G., González-Piana, M., Martigani, M. y Aubriot, L., 2015. Cianobacterias y cianotoxinas en ecosistemas límnicos de Uruguay. En: INNOTEC, 10, pp.9-22.

Brena, B.M., Font, E., Pírez Schirmer, M., Badagian, N., Cardozo, E., Pérez-Parada, A. y Bonilla, S., 2021. Microcystin ELISA in water and animal serum for an integrated environmental monitoring strategy. En: International Journal of Environmental Analytical Chemistry. DOI: https://doi.org/10.1080/03067319.2021.1881073

Chalar, G., 2009. The use of phytoplankton patterns of diversity for algal bloom management. En: Limnologica, 39(3), pp.200-208. DOI:

https://doi.org/10.1016/j.limno.2008.04.001

Chalar, G., Fabián, D., González, M. y Delbene, L., 2010. Limnología de los embalses del Río Negro: Noviembre 2000 - Marzo 2009. Informe [En línea]. Montevideo: Sección Limnología, Facultad de Ciencias, Universidad de la República. [Consulta: 5 de febrero de 2021]. Disponible en:

http://limno.fcien.edu.uy/pactuales/Rio\%20Negro\%20Inforrme\%202000-2009.pdf

Chalar, G., Gerhard, M., González-Piana, M. y Fabián, D., 2014. Hidroquímica y eutrofización en tres embalses subtropicales en cadena. En: Marchovecchio, J.E., Botté, S.E., Freije, R.H., eds. Procesos geoquímicos superficiales en Sudamérica. Bahía Blanca: SiFyQA, pp.121-148.

Chalar, G., Garcia-Pesenti, P., Silva-Pablo, M., Perdomo, C., Olivero, V. y Arocena, R., 2017. Weighting the impacts to stream water quality in small basins devoted to forage crops, dairy and beef cow production. En: Limnologica, 65, pp.76-84. DOI: https://doi.org/10.1016/j.limno.2017.06.002

Chorus, I. y Welker, M., 2021. Toxic cyanobacteria in water. 2nd ed. Boca Ratón: CRC Press. DOI: https://doi.org/10.1201/9781003081449

Conde, D., Gorga, J., Clemente, J., Paradiso, M., De león, L. y Lacerot, G., 1999. Calidad de agua en el embalse Rincón del Bonete, período 1994-1999. Informe final [En línea]. Montevideo: FCIEN, UTE. [Consulta: 2 de febrero de 2021]. Disponible en: http://limno.fcien.edu.uy/cd/html/public/pdf/infotec/Conde-etal1999-BoneteInformeResumenejecutivo.pdf

Conde, D., Paradiso, M., Gorga, J., Brugnoli, E., De León, L. y Mandiá, M., 2002. Problemática de la calidad de agua en el sistema de grandes embalses del Río Negro (Uruguay) [En línea]. Montevideo: CIER 39, pp.51-68. [Consulta: 2 de febrero de 2021]. Disponible en:

http://limno.fcien.edu.uy/cd/html/public/pdf/articulos/Conde-etal-CIER2002.pdf

Conde, D. y Sommaruga, R., 1999. A review of the state of Limnology in Uruguay. En: Gopal, J., Wetzel, R., eds. Limnology in developing countries 2. New Delhi: 
International Scientific Publications/SIL. pp.1-31.

Cremella, B., Huot, Y. y Bonilla, S., 2018. Interpretation of total phytoplankton and cyanobacteria fluorescence from cross-calibrated fluorometers, including sensitivity to turbidity and colored dissolved organic matter. En: Limnology and Oceanography: Methods, 16(12), pp.881-894. DOI: https://doi.org/10.1002/lom3.10290

Cunha, D.G.F., Calijuri, M.do C. y Lamparelli, M.C., 2013. A trophic state index for tropical/subtropical reservoirs (TSItsr). En: Ecological Engineering, 60, pp.126-134. DOI: https://doi.org/10.1016/j.ecoleng.2013.07.058

Davis, J.R. y Koop, K., 2006. Eutrophication in Australian rivers, reservoirs and estuaries a southern hemisphere perspective on the science and its implications. En: Hydrobiologia, 599(1), pp.23-76. DOI: https://doi.org/10.1007/s10750-005-4429-2

De León, L., Paradiso, M., Brugnoli, E., Gorga, J. y Conde, D., 2001. // Muestreo de toxicidad y II Muestreo de calidad de agua en los embalses del Río Negro. Montevideo: Sección Limnología, Facultad de Ciencias, Universidad de la República. (Informe inédito).

Dodds, W.K., Bouska, W.W., Eitzmann, J.L., Pilger, T.J., Pitts, K.L., Riley, A.J., Schloesser, J.T. y Thornbrugh, D.J., 2009. Eutrophication of U. S. freshwaters: Analysis of potential economic damages. En: Environmental Science and Technology, 43(1), pp.12-19. DOI: https://pubs.acs.org/doi/10.1021/es801217q

Estudio Ingeniería Ambiental, 2019. Informe técnico. Respuesta a SIC14-Ecosistemas acuáticos II. Informe técnico. CUECAR S.A. Y BLANVIRA S.A. Exp. 2018/140001011210. Montevideo: EIA. [Consulta: 20 de enero de 2021]. Disponible en: https://www.ambiente.gub.uy/oan/wp-content/uploads/2018/02/22.1-RespuestaSIC-14-Ecosistemas-acu\%C3\%A1ticos-II en.pdf

FAO y Uruguay. Ministerio de Vivienda Ordenamiento Territorial y Medio Ambiente, 2015. Atlas de cobertura del suelo del Uruguay: cobertura del suelo y detección de cambios 2000-2011 [En línea]. Montevideo: MVOTMA. [Consulta: 15 de noviembre de 2020] Disponible en: http://www.fao.org/3/i4372s/i4372s.pdf

Ferrari, G., Pérez, M. del C., Dabezies, M., Míguez, D. y Saizar, C., 2011. Planktic Cyanobacteria in the Lower Uruguay River, South America. En: Fottea, 11(1), 225234.

Furtado, A.L.F.F., Calijuri, M.D.C., Lorenzi, A.S., Honda, R.Y., Genuário, D.B. y Fiore, M.F., 2009. Morphological and molecular characterization of cyanobacteria from a Brazilian facultative wastewater stabilization pond and evaluation of microcystin production. En: Hydrobiologia, 627(1), pp.195-209. DOI:

https://doi.org/10.1007/s10750-009-9728-6 
Gazzano, I., Achkar, M. y Diaz, I., 2019. Agricultural transformations in the southern cone of Latin America: Agricultural intensification and decrease of the aboveground net primary production, Uruguay's case. En: Sustainability, 11(24), 7011. DOI: https://doi.org/10.3390/su11247011

Glibert, P.M., Maranger, R., Sobota, D.J. y Bouwman, L., 2014. The Haber Bosch-harmful algal bloom (HB-HAB) link. En: Environmental Research Letters, 9(10). DOI: https://doi.org/10.1088/1748-9326/9/10/105001

González-Piana, M., Fabian, D., Delbene, L. y Chalar, G., 2011. Toxics blooms of Microcystis aeruginosa in three Río Negro reservoirs, Uruguay. En: Harmful Algal News, 43, pp.16-17.

González-Piana, M., Fabián, D., Piccardo, A. y Chalar, G., 2017. Dynamics of total Microcystin LR concentration in three subtropical hydroelectric generation reservoirs in Uruguay, South America. En: Bulletin of Environmental Contamination and Toxicology, 99(4), pp.488-492. DOI: https://doi.org/10.1007/s00128-017-2158-7

González-Piana, M., Piccardo, A., Ferrer, C., Brena, B., Pírez, M., Fabián, D. y Chalar, G., 2018. Effects of wind mixing in a stratified water column on toxic cyanobacteria and Microcystin-LR distribution in a subtropical reservoir. En: Bulletin of Environmental Contamination and Toxicology, 101, pp.611-616. DOI: https://doi.org/10.1007/s00128-018-2446-x

Goyenola, G., Kruk, C., Mazzeo, N., Nario, A., Perdomo, C., Piccini, C., y Meerhoff, M. 2021. Producción, nutrientes, eutrofización y cianobacterias en Uruguay: armando el rompecabezas. En: INNOTEC, 22, pp.1-33. DOI: https://doi.org/10.26461/22.02

Haakonsson, S., Rodríguez-Gallego, L., Somma, A. y Bonilla, S., 2017. Temperature and precipitation shape the distribution of harmful cyanobacteria in subtropical lotic and lentic ecosystems. En: Science of the Total Environment, 609, pp.1132-1139. DOI: https://doi.org/10.1016/j.scitotenv.2017.07.067

Huisman, J., Codd, G.A., Paerl, H.W., Ibelings, B.W., Verspagen, J.M.H. y Visser, P.M., 2018. Cyanobacterial blooms. En: Nature Reviews Microbiology, 16(8), pp.471-483. DOI: 10.1038/s41579-018-0040-1

IBGE, 2018. Monitoramento da cobertura e uso da terra do Brasil 2014-2016 [En línea]. Río de Janeiro: IBGE. [Consulta: 10 de noviembre de 2020]. Disponible en: https://biblioteca.ibge.gov.br/visualizacao/livros/liv101625.pdf

Illarze, M., 2015. Embalses como incubadoras de cianobacterias: efecto de la residencia del agua y de la disponibilidad de nutrientes. Montevideo: Facultad de Ciencias, Universidad de la República. (Tesis de Grado).

Kruk, C., Martínez, A., Martínez de la Escalera, G., Trinchin, R., M., G., Segura, A.M., Piccini, C., Brena, B., Fabiano, G., Pirez, M., Gabito, L., Alcántara, I., Yannicelli, B., 2019. 
Floración excepcional de cianobacterias tóxicas en la costa de Uruguay, verano 2019. En: INNOTEC, 18, pp.36-68. DOI: https://doi.org/10.26461/18.06

Maavara, T., Parsons, C.T., Ridenour, C., Stojanovic, S., Dürr, H.H., Powley, H.R. y Van Cappellen, P., 2015. Global phosphorus retention by river damming. En: Proceedings of the National Academy of Sciences of the United States of America, 112(51), pp.15603-15608. DOI: https://doi.org/10.1073/pnas.1511797112

Moss, B., 2008. Water pollution by agriculture. En: Philosophical Transactions of the Royal Society B: Biological Sciences, 363(1491), pp.659-666. DOI: https://doi.org/10.1098/rstb.2007.2176.

Paerl, H.W., 2017. Controlling cyanobacterial harmful blooms in freshwater ecosystems. En: Microbial Biotechnology, 10(5), pp.1106-1110. DOI: https://doi.org/10.1111/1751-7915.12725

Paerl, H.W. y Otten, T.G., 2013. Harmful Cyanobacterial blooms: causes, consequences, and controls. En: Microbial Ecology, 65(4), pp.995-1010. DOI: https://doi.org/10.1007/s00248-012-0159-y

Palmer, M. y Ruhi, A., 2019. Linkages between flow regime, biota, and ecosystem processes: Implications for river restoration. En: Science, 365(6459). DOI: https://doi.org/10.1126/science.aaw2087

Patrone, J.C., 2014. Hidroelectricidad - Uruguay. Informe Final. [En línea]. Buenos Aires: Programa Marco para la Gestión Sostenible de los Recursos Hídricos de la Cuenca del Plata. [Consulta: 11 de noviembre de 2020]. Disponible en: https://cicplata.org/wp-content/uploads/2019/08/HidroelectricidadUruguay Julio-Patrone.pdf

Pérez, M.C., Bonilla, S. y Martínez, G., 1999. Phytoplankton community of a polymictic reservoir, La Plata River basin, Uruguay. En: Revista Brasileira de Biologia, 59(4), pp.535-541. DOI: https://doi.org/10.1590/S0034-71081999000400002

Pérez, M. C., 2002. Fitoplancton del Río Negro, Uruguay. En: Limnetica, 21(1-2), pp.81-92.

Ramankutty, N., Mehrabi, Z., Waha, K., Jarvis, L., Kremen, C., Herrero, M. y Rieseberg, L.H., 2018. Trends in global agricultural land use: implications for environmental health and food security. En: Annual Review of Plant Biology, 69(604), pp.789-815. DOI: https://doi.org/10.1146/annurev-arplant-042817-040256

Rangel, L.M., Silva, L.H.S., Rosa, P., Roland, F. y Huszar, V.L.M., 2012. Phytoplankton biomass is mainly controlled by hydrology and phosphorus concentrations in tropical hydroelectric reservoirs. En: Hydrobiologia, 693(1), pp.13-28. DOI: https://doi.org/10.1007/s10750-012-1083-3

Reynolds, C.S., 2006. Ecology of phytoplankton. Cambridge: Cambridge University Press. 
ISBN: 9780521605199.

Sinha, E., Michalak, A.M., Calvin, K.V. y Lawrence, P.J., 2019. Societal decisions about climate mitigation will have dramatic impacts on eutrophication in the 21 st century. En: Nature Communications, 10(1), pp.939. DOI: https://doi.org/10.1038/s41467019-08884-w

Steffensen, D.A., 2008. Economic cost of cyanobacterial blooms. En: Cyanobacterial harmful algal blooms: state of the science and research needs. New York: Springer. pp.855-865. https://doi.org/10.1007/978-0-387-75865-7 37

Tundisi, J.G., Rocha, O., Matsumura-Tundisi, T. y Braga, B., 1998. Reservoir management in South America. En: International Journal of Water Resources Development, 14(2), pp.141-155. DOI: https://doi.org/10.1080/07900629849367

Uruguay. Ministerio de Medio Ambiente, 2020. Observatorio ambiental nacional: calidad de agua [En línea]. Montevideo: Ministerio de Ambiente. [Consulta: 08 de junio de 2021]. Disponible en: https://www.dinama.gub.uy/oan/datos-abiertos/calidadagual

Uruguay. Ministerio de Vivienda, Ordenamiento Territorial y Medio Ambiente, DINAMA, 2019a. Ref.: CUECAR S.A y BLANVIRA S.A. Solicitud de Autorización Ambiental Previa para su proyecto Planta de celulosa y zona franca en el departamento de Durazno. Informe final. [En línea]. Montevideo: DINAMA. [Consulta: 20 de abril de 2020].

Disponible en: https://www.ambiente.gub.uy/oan/wpcontent/uploads/2018/02/20190514-IF-UPM-FINAL.pdf

Uruguay. Ministerio de Vivienda Ordenamiento Territorial y Medio Ambiente, DINAMA, 2019b. Red de Monitoreo Costero. Monitoreo de playas. Quinquenio 2013-2018 y temporada 2018-2019. Informe técnico [En línea]. Montevideo: DINAMA. [Consulta: 9 de febrero de 2021]. Disponible en: https://www.dinama.gub.uy/oan/documentos/Informe_monitoreo_calidad_de_play as_2018-2019.pdf

Uruguay. Ministerio de Vivienda Ordenamiento Territorial y Medio Ambiente, DINAMA, 2018. Calidad ambiental de la cuenca del Río Negro 2009 - 2017[En línea]. Montevideo: DINAMA. [Consulta: 20 de enero de 2021]. Disponible en: https://www.gub.uy/ministerio-ambiente/comunicacion/publicaciones/informecalidad-ambiental-del-rio-negro-2009-2017.

Uruguay. Ministerio de Vivienda Ordenamiento Territorial y Medio Ambiente, DINAMA, 2012. Monitoreo y evaluación de calidad de agua. Plan para la definición de una línea de base del Río Negro. Reporte de resultados del período. Informe de consultoría 14 [En línea]. Montevideo: DINAMA-PNUD. [Consulta: 12 de noviembre de 2020]. Disponible en: https://www.gub.uy/ministerioambiente/comunicacion/publicaciones/monitoreo-evaluacion-del-rio-negro-2011. 
Uruguay. Decreto 253/979, de 9 de mayo de 1979. Diario Oficial, 31 de mayo de 1979, p.1479.

Valderrama, J.C., 1981. The simultaneous analysis of total nitrogen and total phosphorus in natural waters. En: Marine Chemistry,10(2), pp.109-122. DOI:

https://doi.org/10.1016/0304-4203(81)90027-X

van Apeldoorn, M.E.V., Egmond, H.P., Speijers, G.J.A. y Bakker, G.J.I., 2007. Toxins of cyanobacteria. En: Molecular Nutrition \& Food Research, 51(1), pp.7-60. DOI:

https://doi.org/10.1002/mnfr.200600185 